\title{
INTRODUCTION: SPECIAL ISSUE ON THE AUSTRALIAN EVENT SYMPOSIUM
}

\author{
ROB HARRIS,* DEBORAH EDWARDS,* CARMEL FOLEY,† AND KATIE SCHLENKER* \\ *Australian Centre for Event Management, UTS Business School, \\ University of Technology, Sydney, Sydney, Australia \\ †Management Discipline Group, UTS Business School, \\ University of Technology, Sydney, Sydney, Australia
}

The 2012 Australian Event Symposium represented a collaboration between the Australian Centre for Event Management, University of Technology, Sydney, the Australian Event Awards, and the International Special Events Society. Over the 3 days of the symposium industry professionals and academics explored a diverse range of issues, including: current and future industry challenges; sustainability practices; leadership; creativity, innovation, and design thinking; the economic impact of event-related infrastructure; event tourism strategies; volunteering; social capital building and community engagement; risk management; and designing inclusive event spaces. These matters were examined through workshops, academic paper presentations, panels, and round tables. Additionally, a Think Tank of leading event practitioners and academics from across Australia was held prior to the Symposium to explore issues with the potential to impact the industry's future. The outcomes of this event were later fed into the conference for attendee discussion.

The guest editors of this special edition have chosen five academic articles that were either presented at the Symposium or that later emerged from it as a result of discussions and arguments presented there. Additionally, these articles were selected because they sought to explore areas not frequently addressed in the event management literature. The first of these, by Edwards, Foley, Dwyer, Schlenker, and Hergesell, examines the localized economic impact of a large indoor entertainment center-the Sydney Entertainment Centre. Its findings highlight the value of such facilities to the areas they are located in, as well as to those precincts adjacent to them. The second, by Mair, is an exploratory research study concerning the use of events as spaces for proenvironmental behavior messaging. This article makes the case that there is meaningful potential for particular events to become environmental learning spaces for their attendees. In the third article, Darcy, Dickson, and Benson explore the experiences of volunteers at the London 2012 Olympic and Paralympic Games who identified themselves as having access needs and/ or disabilities. While they note that some volunteers provided feedback consistent with an overall positive experience, a number reported significant 
organizational, environmental, and structural issues that compromised their engagement with the event. Based on their findings, they suggest a range of actions linked to future event planning processes and broader macropolicies in the disability area. The penultimate article by Mackellar examines the Bleach Festival, a "fringe" style event that is positioned between two major surf events (Quiksilver/ Roxy Pro and Burleigh Pro) that are held annually in Coolangatta, Queensland. This study evaluates the success of the festival against its own objectives of tourism extension, destination brand development, and local artist engagement. It makes a number of observations about the value of developing cultural and artistic augmentations to sport events in situations where there is a relationship between a sport and its physical environment at a given location. The article by Harris, Edwards, and Homel deals with the ongoing challenge faced by many event and venue managers as they seek to control patron/attendee alcohol and drug use. This study, which involved in-depth interviews with police, event and venue managers, state alcohol licensing bodies, security firms, and relevant industry associations, spans three Australian states. Emerging from the inquiry are a number of key variables with the potential to impact the degree to which a given event or venue may present challenges in this area. Additionally, it highlights the types of control practices available to event and venue managers as they seek to minimize the potential for personal harm, violence, or social disruption.

This issue also includes a summary of the key matters that emerged from a national industry Think Tank conducted as a lead-in event to the Symposium. This event saw a number of issues identified as important for the industry going forward, specifically: global competitiveness; event evaluation practices; sector collaboration and representation; government regulation; and awareness of the industry's economic significance.

In addition to the special material, three regular issue research notes are also included. 